\title{
Cagliostro em l'affaire du collier de la reine: entre a história, a literatura e o cinema
}

\author{
Maria Gabriella Flores Severo Fonseca ${ }^{\mathrm{i}}$ \\ Sidney Barbosa ${ }^{\text {ii }}$
}

\section{RESUMO}

Cagliostro (1743-1795) foi uma figura histórica envolvida na trama social conhecida como l'affaire du collier de la reine, ocorrida em 1785 na Corte de Luís XVI e de Maria Antonieta, retratada no romance histórico Le Collier de la reine (1850-1852) de Alexandre Dumas, pai. Na narrativa, o autor francês dialoga com arquivos históricos a respeito do personagem e é bastante inventivo na sua caracterização, apresentando-o como um agente inoportuno de um episódio político considerado preparador da queda da Bastilha. O enigmático e influente Cagliostro, inventado por Dumas, tornou-se transficcional, sendo retomado no filme Black Magic/ Cagliostro (1949). Nessa obra, o personagem passou a transitar alterado e renovado, indo do texto ao filme parcial ou totalmente modificado, enriquecendo mais ainda o repertório adquirido.

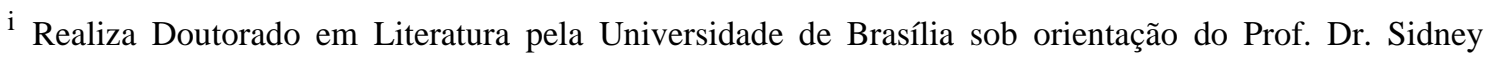
Barbosa. Possui Mestrado em Letras e Artes pela Universidade do Estado do Amazonas (2017), Especialização em Cinema e Linguagem audiovisual pela Universidade Vale do Rio Verde de Três Corações (2021), Graduação em Licenciatura em Letras Português pela Universidade Federal do Pará (2014). É professora de Língua Portuguesa e Literatura na Secretaria Municipal de Educação de Manaus e na Secretaria de Estado de Educação e Qualidade de Ensino do Amazonas. É membro do grupo de pesquisa Núcleo de Pesquisas em Linguística e Literatura. Desenvolve suas pesquisas em Literatura do século XIX, com ênfase em Romantismo, romances-folhetins e Alexandre Dumas; Literatura e outras Artes; Literatura e Cinema. ORCID: http://orcid.org/0000-0003-1487-0480 / gabriellafloress@hotmail.com
}

\footnotetext{
ii Licenciou-se em Letras (1975), na formação Português-Francês, pela Faculdade de Filosofia Ciências e Letras de Franca (SP), curso superior estadual que se tornou depois uma Unidade da UNESP. Possui Especialização no Ensino de Língua Francesa (1977) e Maîtrise en Lettres Modernes (1982), ambas pela Université de Poitiers, Doutorado em Língua e Literatura Francesa (1990), pela Universidade de São Paulo e Livre-Docência em Teoria e Crítica do Romance (2005), pela Faculdade de Ciências e Letras da UNESP, Campus de Araraquara. Realizou estágio de pós-doutorado (1998-1999) na Université de Paris VIII - Vincennes-Saint Denis, sob a supervisão de Jacques Ardoino e Jean Verrier e na Universidade de São Paulo (2016-2017), sob a supervisão de John Milton. Atualmente é professor adjunto IV, efetivo, de Literatura Francesa do Departamento de Teoria Literária e Literaturas - TEL - da Universidade de Brasília, no Distrito Federal. No Pós-Lit/UnB atua na linha de pesquisa "Literatura e outras Artes". Aplica-se à reflexão sobre Literatura e outras artes (pintura, fotografia, música, arquitetura, teatro, quadrinhos, dança e cinema), aos estudos sobre o romance em geral, ao francês, em particular e à representação da Natureza na Literatura, com ênfase no estudo da paisagem. Pesquisa também o movimento simbolista e a história do livro, da leitura e das bibliotecas. É líder, juntamente com Ozíris Borges Filho da Universidade Federal do Triângulo Mineiro, do Grupo de Pesquisa inter-institucional TOPUS, dedicado ao estudo do espaço na literatura e em outras artes. Coordena igualmente, com a cooperação de Alessandra Matias Querido, da Universidade Católica de Brasília, o Grupo de Pesquisa LiterArtes, consagrado ao estudo das relações entre Literatura e outras artes. ORCID: https://orcid.org/0000-0001-8976-563X / lucidney@uol.com.br
} 
Palavras-chave: Personagem; Transficcionalidade; Adaptação; Literatura e Cinema; Cagliostro.

\section{RÉSUMÉ}

Cagliostro (1743-1795) fut une figure historique impliquée dans la trame sociale connue comme l'affaire du collier de la reine, survenue en 1785 à la Cour de Louis XVI et de Marie-Antoinette, dépeinte dans le roman historique Le Collier de la reine (1850-1852) d'Alexandre Dumas, père. Dans le récit, l'auteur français dialogue avec les archives historiques sur le personnage et est assez inventif dans sa caractérisation, le présentant comme un agent inopportun d'un épisode politique considéré comme préparateur de la chute de la Bastille. L'énigmatique et influent Cagliostro, inventé par Dumas, est devenu transfictionnel, repris dans le film Black Magic / Cagliostro (1949). Dans cette œuvre, le personnage est modifié et renouvelé, allant du texte au film partiellement ou totalement modifié, enrichissant encore le répertoire acquis.

Mots-clés: Personnage; Transfictionnalité; Adaptation; Littérature et cinéma; Cagliostro.

\section{INTRODUÇÃO}

Figura 1: Comte de Cagliostro

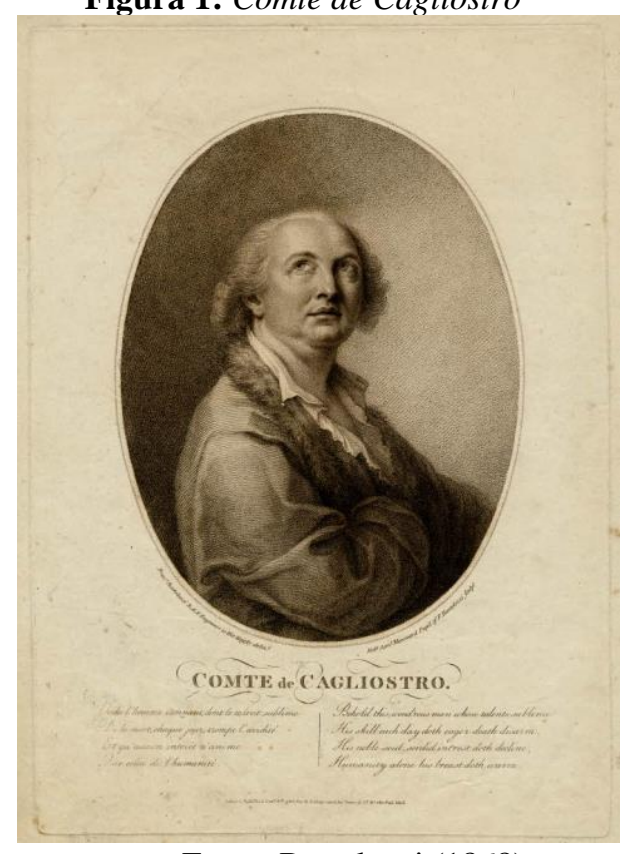

Fonte: Bartolozzi (1868) 
Cagliostro (1743-1795), personagem histórico, místico influente do século XVIII, viajante cosmopolita pelas nações europeias, figura central de vários boatos, envolvendo suas práticas místicas, compreendidas, por alguns, como charlatanismo e, por outros, como curas milagrosas. De qualquer forma, segundo Eco (2006), em Migrações de Cagliostro, o personagem estabeleceu-se na esfera de mito ou de lenda, o que pode ser percebido pela cagliostrofilia maçônica ${ }^{1}$ que compreendemos ser sua constante representação em obras culturais diversas, seja nas artes pictóricas, musicais, literárias ou cinematográficas. Como exemplo, podemos citar suas representações literárias no ciclo folhetinesco Mémoires d'un médecin (1846-1855), de Alexandre Dumas, em Conde Cagliostro (1921), de Alexei Tolstoi, e, em O pêndulo de Foucault (1988), de Umberto Eco, para citar algumas célebres.

Dentre todos os episódios nos quais esteve envolvido, o l'affaire du collier de la reine foi, possivelmente, o maior responsável pela transmigração de sua figura histórica para tema ficcional. Isso aconteceu porque, segundo Tatin-Gourier (1994, p. 13; tradução nossa), em Cagliostro et l'affaire du collier: pamphlets et polémiques, Cagliostro, por meio de sua participação nesse episódio, “cristalizou na opinião pública um imaginário da corrupção ao mesmo tempo social, política e intelectual". ${ }^{2}$ Por isso, ele foi tido como um indivíduo partícipe das elites políticas e sociais corruptas e como o sedutor de uma sociedade supostamente esclarecida, mas ainda permeável ao "charlatanismo moderno".

Segundo Haven (2005), em sua obra Le Maître Inconnu, Cagliostro: étude historique et critique sur la haute magie, Cagliostro, que já era um influente místico na Europa, quando chega em Paris em 1785, obteve ali também um sucesso triunfal. Foi envolvido no escândalo do colar da rainha por ser uma espécie de conselheiro e mentor do cardeal de Rohan, Arcebispo de Estrasburgo. A Condessa Valois de la Motte, a principal suspeita do roubo do colar, defende-se das acusações impetradas contra si, incriminando o Cardeal e Cagliostro. Considerava que o místico era a pessoa certa para se acusar, visto ser considerado "um mago misterioso, que distribui dinheiro em torno de si, sem recursos conhecidos, íntimo do cardeal, seu confessor" (HAVEN, 2005, p. $163)$.

Contrariando o que pensava de la Motte, Cagliostro ganhou o apreço da opinião pública, que era entusiasta por seu voto de liberdade. Seus depoimentos nos 
interrogatórios eram divulgados em panfletos e tiveram muito apelo popular. Enfim, em 31 de maio, "o julgamento foi exarado, proclamando o cardeal e Cagliostro inocentes, dando-lhes a quitação honrosa, ordenando sua libertação com a impressão e afixação do decreto e a destruição dos panfletos escritos contra ele" (HAVEN, 2005, p. 169). Cagliostro, que fora preso na Bastilha para aguardar o resultado do julgamento, foi solto e o público o esperava na porta da prisão para aplaudi-lo:

De Launay abriu as portas da Bastilha a seu prisioneiro. Apesar do avançado da hora, a manifestação foi grandiosa: 8 a 10 mil pessoas rodeavam sua casa; gritos de alegria, batida de tambores, iluminações ofuscavam; era quase uma revolução em germe (HAVEN, 2005, p. 174).

Haven (2005, p. 182) afirma que a rainha ficou furiosa por Cagliostro e o cardeal terem sido inocentados e "o entusiasmo da multidão pelos dois acusados a ferira como um insulto pessoal". O místico, após a ordem de seu exílio de Paris pelos monarcas, dirigiu-se à Inglaterra onde escreveu a Lettre au peuple français em 1786. Nessa carta, Cagliostro (1786) afirma que a Bastilha viria a se tornar um passeio público, que reinaria na França um príncipe que aboliria os privilégios, convocaria os estados gerais e restabeleceria a verdadeira religião, o que foi considerado pelo escrivão do Santo Ofício, Giovanni Barbieri, no Compendio da vida e feitos de José Balsamo chamado o Conde de Cagliostro, como um sinal profético da Revolução Francesa, iniciada em 1789 com a queda da Bastilha, ocorrida no dia 14 de julho daquele ano.

Conhecendo a importância desse personagem para o imaginário francês desde sua participação no l'affaire e mesmo por sua reconhecida influência nas cortes europeias no século XVIII, o escritor francês Alexandre Dumas retoma-o no seu ciclo romanesco Mémoires d'un médecin, dedicando a segunda parte, que se refere ao romance Le Collier de la reine (1848-1850), a tratar do famoso l'affaire e da participação de Cagliostro nele.

O personagem é retomado no romance como o líder de um complô revolucionário que tinha como intuito a derrubada da monarquia francesa. O filme de produção ítalo-americana Black Magic/Cagliostro (1949), direção de Gregory Ratoff, inspirado na narrativa dumasiana, retomou o l'affaire e as figurações de Cagliostro segundo a proposição de Alexandre Dumas. Para a análise a que nos propomos realizar nesse artigo, o conceito de adaptação será ampliado, pois não buscamos abordar o filme 
apenas sob uma perspectiva comparativista em relação à obra dumasiana, mas nos basearemos no conceito de transficcionalidade de Saint-Gelais (2001). Essa concepção, a nosso ver, constitui uma forma de compreender as relações palimpsestuosas existentes entre literatura e cinema.

\section{L'AFFAIRE DU COLLIER DE LA REINE: A HISTÓRIA COMO MATÉRIA DO ROMANCE-FOLHETIM DUMASIANO}

A História era a grande fonte para Alexandre Dumas, que costumava frequentar os arquivos em busca de material para escrever seus dramas e romances. Conforme observa Mendes (2007), o escritor era um faiseur de l'histoire, pois criava com suas obras um verdadeiro mosaico histórico da França, intercalando, em suas narrativas, seu conhecimento das leituras dos textos de memorialistas, dos livros de Michelet, por exemplo, de quem era um grande admirador, ao seu senso de manter o interesse do público leitor.

Dumas percebe sua função de que, como romancista histórico, podia descrever a história francesa de forma a divertir e, ao mesmo tempo, a ensinar o povo por meio de uma linguagem simples e de uma escrita atraente. Assim, para Marlyse Meyer (1996, p. 67), no clássico Folhetim: uma história, Dumas, "cavouca segredos de alcova e mexericos de outros tempos, ressucita espadachins e suas bravatas, ministros, rainhas, lançando o caudal do folhetim histórico, aquele que para muitos de nós fez as vezes da verdadeira História".

Em sua Lettre à Jules Michelet, inserida no romance Le Docteur mysterieux (1872), Alexandre Dumas introduz uma reflexão sobre este seu papel de divulgar a história entre as massas. Ledda e Schopp (2020) reproduzem essa sua ponderação no Cahier de l'Herne, $n^{\circ}$ 131: Alexandre Dumas. Na carta, o autor afirma ter assumido a tarefa de introduzir a história nacional em suas obras, e que sua popularidade havia sido colocada a serviço da educação pública. Orgulha-se de ter recebido de Michelet, a quem considera um mestre, as seguintes palavras: "Ensinaste mais história ao povo do que todos os historiadores juntos" (DUMAS, 1860 apud LEDDA; SCHOPP, 2020, sem paginação; tradução nossa). ${ }^{3}$ Tal elogio o tocou profundamente, pois compreendia que "Ensinar história ao povo, é dar-lhe sua carta de alforria, seu título de nobreza, dois documentos inatacáveis e contra as quais não prevalecerá a noite do dia 4 de agosto"4 
(Ibid., sem paginação; tradução nossa). ${ }^{5} \mathrm{O}$ escritor crê, assim, que sua produção literária pode democratizar o conhecimentos aos seus tão fiéis leitores.

Foi com essa intenção democratizante do conhecimento que Alexandre Dumas abordou, em seu ciclo romanesco Mémoires d'un médecin, a história de um movimento que é considerado um dos principais acontecimentos da História moderna mundial, a Revolução Francesa.

Saminadayar-Perrin (2005, p. 141; tradução nossa), em insaisissable corps $d u$ peuple dans le cycle révolutionnaire d'Alexandre Dumas, afirma que a tetralogia romanesca Mémoires d'un médecin, dedicada à Revolução "apresenta-se claramente como uma súmula narrativa que resume todas as análises da historiografia romântica". 6 Além disso, essa espécie de homenagem a esse momento histórico adquire um sentido no contexto político da época em que vivia o autor, visto o ciclo folhetinesco ter sido escrito entre 1846 a 1855, período de outra efervescência política, devido aos acontecimentos da Primavera dos povos, iniciada em fevereiro de 1848, e igualmente da tomada de poder, por meio de um golpe de estado, por Napoleão III, algum tempo depois de ser eleito Presidente da República Francesa.

Nessa tetralogia, o ciclo revolucionário é dividido em quatro títulos, ou seja, quatro romances, a saber, Joseph Balsamo, Le collier de la reine, Ange Pitou e La Comtesse de Charny. Esta é a lista, embora alguns editores acrescentem o romance Le Chevallier de Maison-Rouge como fazendo parte do ciclo, o que não deve ter sido a intenção do autor Alexandre Dumas, uma vez que publicou esse romance antes de todos, em 1845. Segundo Bassan (2003), em seu artigo Joseph Balsamo: une pièce posthume d'Alexandre Dumas père, os romances Joseph Balsamo, Le Collier de la Reine e Ange Pitou, escritos em colaboração com o historiador Auguste Maquet, publicados e distribuídos pelo jornal La Presse, tornaram-se enormes sucessos na França. La Comtesse de Charny, foi escrito somente por Dumas, durante seu exílio em Bruxelas, após Napoleão III relizar o golpe de estado e ascender ao poder ditatorial, em 1851.

No que se refere ao romance Le Collier de la reine, a história desenrola-se no momento do reinado de Luís XVI e de Maria Antonieta, por volta de 1785, e apresentase, como trama central, o l'affaire du collier de la reine, imbróglio em que maldosamente a rainha e o próprio Cagliostro foram envolvidos involuntariamente. Os 
principais personagens envolvidos na história dumasiana são: A condessa Jeanne Valois de la Motte, uma nobre falida, mas que possuía um nome de prestígio e que acreditava não receber a devida consideração por parte da monarquia; a rainha Maria Antonieta, o cardeal de Rohan, Cagliostro e Nicola Legay.

Na obra, condessa de la Motte, sabendo do amor secreto do Cardeal de Rohan por Maria Antonieta, cria uma trama para enganá-lo e convencê-lo a tornar-se o fiador na compra de um colar, que, supostamente seria para Maria Antonieta. De la Motte envia ao cardeal cartas apaixonadas da rainha e arma um encontro amoroso às escuras entre a rainha e o cardeal. Porém, tratava-se de um engano completo, as cartas eram forjadas pela própria de la Motte e quem havia ido ao encontro com o cardeal era Nicola Legay, uma atriz que tinha aparência física muito semelhante a Maria Antonieta. O plano, que estava seguindo seu curso perfeito, foi descoberto quando os joalheiros exigiram o pagamento do colar pela rainha. A condessa e o cardeal foram acusados de traição contra os monarcas. Como forma de escapar à condenação, a condessa acusa Cagliostro, que tinha sua reputação colocada sob suspeita por suas práticas místicas.

Cagliostro, por outro lado, por ser mentor de um plano da derrubada da monarquia, relatado no avant-propos do romance Joseph Balsamo, percebeu que seu envolvimento naquele episódio seria uma forma de acelerar a desmoralização dos reis da França e, consequentemente, sua queda:

\footnotetext{
Madame de La Motte se enganou em cada um dos seus cálculos. Cagliostro não se confundiu em nenhum dos seus. Somente durante sua estada na Bastilha permitiu-se, finalmente, trabalhar abertamente pela queda dessa monarquia que, desde há tantos anos, ele minava sorrateiramente com o ilusionismo e os expedientes ocultistas (DUMAS, 1853b, p. 249; tradução nossa). ${ }^{7}$
}

Cagliostro estava certo. Após o julgamento e a declaração de inocência do cardeal e do mágico, a opinião pública voltou-se contra os monarcas, enquanto o cardeal de Rohan e Cagliostro foram vistos como vítimas da intriga da rainha Maria Antonieta e da condessa de la Motte, sua cúmplice.

Alexandre Dumas mostra, desse modo, em sua obra que a participação do personagem Cagliostro no affaire foi decisiva para sua figuração como personagem de um conflito político-ideológico, que, supostamente, ajudou a colocar em xeque o poder da Monarquia. Porém, na narrativa dumasiana, o místico setecentista Cagliostro agiu 
além dos bastidores dos acontecimentos do escândalo do colar, pois aparece em cenas como hipnotista, mágico e vidente. Além disso, tem constantemente questionado seus poderes por certos personagens da trama, que o definem como um charlatão.

\begin{abstract}
O senhor de Crosne sabia de Cagliostro tudo o que um experimentado chefe de polícia pode saber de um homem que morava na França de então, e isso não era pouco. Conhecia os nomes falsos que usara no passado, todos os seus segredos de alquimista, de homem do magnetismo; conhecia a sua pretensão de ser mestre da teoria da ubiquidade e da adivinhação, da cura definitiva das doenças: considerava-o como um perfeito charlatão com pose de grande senhor (DUMAS, 1853b, p. 230; tradução nossa). ${ }^{8}$
\end{abstract}

É importante pontuar que a referência ao charlatanismo de Cagliostro trata-se de uma intenção dialógica do escritor francês, que se volta a uma tradição de discursos históricos publicados na época em que Cagliostro vivia e em momentos posteriores. ${ }^{9} \mathrm{O}$ autor, na verdade, longe de apresentar um discurso condenatório do personagem, durante toda a obra, joga com as contradições dele, mostrando que, ao mesmo tempo, possuía poderes e que era, por isso mesmo, considerado um indivíduo perigoso, que deveria ser difamado. $\mathrm{O}$ autor reconhecia a importância de se levar em consideração toda a gama de interesses e de ideologias envolta por esses discursos, afinal, o personagem histórico foi condenado pela Santo Ofício como herege e praticante da Maçonaria.

Além disso, pode-se dizer que, nessa obra, Alexandre Dumas elabora a representação literária mais famosa de Cagliostro. Pela popularidade que teve a empreitada folhetinesca, Dumas contribuiu sobremaneira para efetivar a figura de Cagliostro no imaginário cultural da população, desenvolvendo um tipo já maravilhoso por si mesmo, acrescentando à sua representação traços pertencentes a outros personagens histórico-lendários, como Saint-Germain, Franz Mesmer e Fausto.

Esse personagem e sua participação no affaire foram retomados no filme Black Magic/Cagliostro (1949), de Gregory Ratoff, com cenas dirigidas por Orson Welles. É importante pontuar que existem outros filmes que abordam o episódio do colar da rainha, porém, focamo-nos naquele que, assim como o romancista francês, deu destaque ao personagem Cagliostro em seu enredo.

Ao deslocarmos nosso ponto de vista de uma perspectiva comparativista de adaptação, baseando-nos no conceito de transficcionalidade proposto por Saint-Gelais (2011), podemos investigar como esse filme interpreta a participação de Cagliostro no 
l'affaire du collier de la reine e a partir do que ele se delineia no romance de Alexandre Dumas.

\section{RELAÇÕES TRANSFICCIONAIS ENTRE A LITERATURA E O CINEMA: UMA PROPOSTA NÃO COMPARATIVISTA NO ESTUDO DE ADAPTAÇÕES}

A teoria da adaptação tem sido frequentemente revisitada por pesquisadores no campo da literatura, do cinema e das artes em geral. Estudos recentes têm se direcionado no sentido de não se estabelecer uma mera comparação entre a obra literária e sua adaptação, mas sim em compreender todo o processo em uma rede dialógica que pode gerar traduções, adaptações ou interpretações capazes, inclusive, de não dar conta da fidelidade ao original. Nesse sentido, Stam, em A Literatura através do cinema (2008), propõe que se reflita sobre uma dimensão mais ampla para se pensar o conceito de adaptação, uma vez que:

\footnotetext{
A teoria da adaptação dispõe de um rico universo de termos e tropos tradução, realização, leitura, crítica, dialogização, canibalização, transmutação, transfiguração, encarnação, transmogrificação, transcodificação, desempenho, significação, reescrita, detournement (STAM, 2008, p. 21).
}

Trata-se de um universo de possibilidades que se relacionam com os conceitos de intertextualidade e de dialogismo, de Bakhtin (1997) e de Kristeva (1969), e que enfatizam a interminável permutação de traços textuais, compreendida como constantes respostas de um enunciado em relação a outros. Esse dialogismo intertextual é a base para que Stam (2008) elabore sua teoria sobre adaptação. Para o autor, necessariamente, ela deve transcender de muito a ideia de "fidelidade ao original", pois "fidelidade" não é o tropo adequado no que se refere à teoria da adaptação, visto se tratar sempre de "uma leitura" do texto-fonte "inevitavelmente parcial, pessoal, conjuntural" (STAM, 2008, p. 21). Além disso, observa que, necessariamente, uma adaptação será sempre diferente da fonte, já que o meio de comunicação, ou mídia, foi alterado.

Genette (2010, p. 7), em sua obra Palimpsestos: a literatura de segunda mão, aponta a rede de relações transtextuais que podem ser estabelecidas entre elas, tais como 
a intertextualidade, a paratextualidade, a metatextualidade e a arquitextualidade. Segundo esse teórico literário, um palimpsesto ou "um pergaminho cuja primeira inscrição foi raspada para se traçar outra, que não a esconde de fato, de modo que se pode lê-la por transparência", relaciona-se diretamente com o conceito de hipertexto, também definido como "literatura de segunda mão", pois se refere a essa derivação de um texto a outro, que pode se estabelecer por meio de dois regimes: transformação ou imitação.

Saint-Gelais (2011), em sua obra Fictions transfuges: la transficionnalité et ses enjeux, baseia-se igualmente na teoria de palimpsesto de Genette. Porém, avança em relação aos conceitos de intertextualidade e a hipertextualidade no que tange a relação da literatura com as outras artes, abordando o fenômeno da transficcionalidade. Esse palimpsesto ao segundo grau permite aos protagonistas expandir o mundo ficcional de uma arte para o universo das outras artes, abrangendo, por exemplo, o cinema, o balé, a televisão, os quadrinhos, a ópera etc. Dessa forma, compreende a transficcionalidade como um:

\footnotetext{
fenômeno pelo qual, no mínimo, dois textos de um mesmo autor ou não, relacionam-se conjuntamente com uma mesma obra ficcional, quer seja pela retomada de personagens, prolongamento de um enredo já conhecido ou compartilhamento de um universo ficcional (SAINT-GELAIS, 2011, p. 7; tradução nossa). ${ }^{10}$
}

A maioria das transficções são também comentários sobre a obra ou sobre o cânone de onde essas obras emanam. Nesse sentido, são diferentes das conhecidas adaptações, pois da ficção original se cria uma ficção secundária e vertiginosa. Por isso, podemos entender que o conceito de transficcionalidade permite ampliar o horizonte intertextual/hipertextual das obras de arte. Isso ocorre uma vez que os personagens, objetos, cidades, sobrenomes tornam-se por si mesmos objeto de estudo no campo da intermidialidade. E esta permite "cruzar os campos normalmente desconexos pela compartimentação acadêmica e por certos preconceitos que existem fortemente ainda" (SAINT-GELAIS, 2011, p. 9; tradução nossa). ${ }^{11}$

Nesse sentido, ao nos debruçarmos sobre a obra fílmica a ser cotejada, buscamos compreender como se estabelecem relações transficcionais em torno da figura do Cagliostro dumasiano. Nossa análise tem por intuito relacionar a narrativa romanesca de Le Collier de la reine, a partir do papel central de Cagliostro, em diálogo com o 
filme Black Magic/Cagliostro (1949). Dessa forma, será possível vislumbrar como esse personagem histórico-ficcional, tornado lendário, aparece em sua faceta de líder de um complô político, tal como foi apresentado e proposto na trama dumasiana.

\subsection{A transficcionalidade do Cagliostro dumasiano em Black Magic/ Cagliostro} (1949)

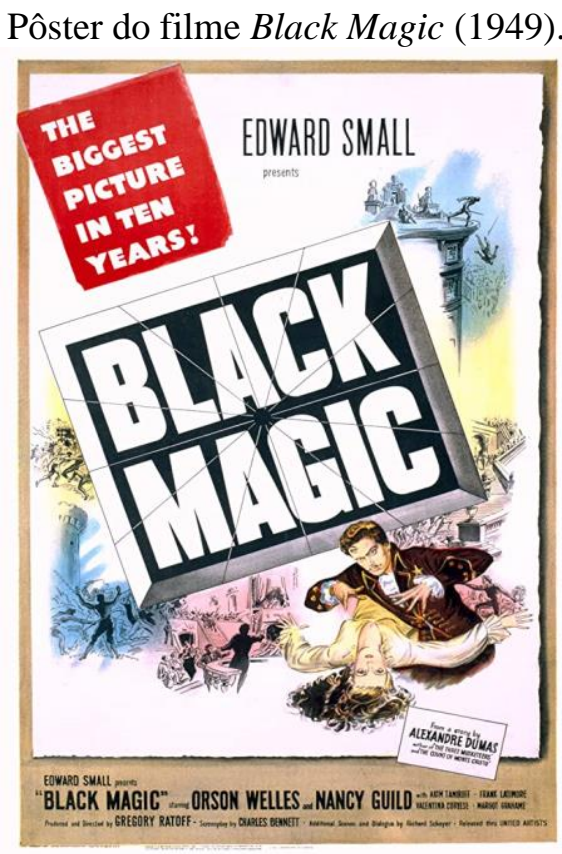

Fonte: IMDB (1949)

O filme Black Magic/Cagliostro (1949), produção de Edward Small e filmado nos estúdios Scalera em Roma, foi realizado por Gregory Ratoff, com algumas cenas dirigidas por Orson Welles. A obra fílmica foi lançada anunciando-se como uma adaptação do ciclo romanesco Mémoires d'un médecin, de Alexandre Dumas. Porém, interpretamos que não contempla todo o ciclo, fazendo referência apenas aos dois primeiros romances da série: Joseph Balsamo, por abordar a história do casal Cagliostro e Lorenza Feliciani, e Le Collier de la reine, por apresentar o envolvimento do personagem no affaire.

Para Bazin (2005), na obra Orson Welles, o filme Black Magic/Cagliostro é resultado da intenção de Welles de explorar seu lado comercial de ator e de realizar projetos que "falassem ao seu coração", pois, muitas vezes, a indústria cinematográfica americana o coibia. Dessa forma, o reconhecido diretor e ator aceitou, pela quantia de 
cem mil dólares, atuar como o personagem Cagliostro no filme, com a condição de que pudesse dirigir as cenas em que figurava. Para Carrega (2015), em seu artigo "Orson Welles y el cine de Hollywood en la década de 1940”, o filme Black Magic/Cagliostro (1949, p. 89) acaba sendo influenciado pela estilística de Welles. O que se pode constatar é a utilização de ângulos baixos de filmagem "aliados à profundidade de campo e um estilo de composição barroco com a utilização expressiva do claro-escuro e uma abundância de planos sobrecarregados de objetos". Além disso, segundo o autor, por ser narrado num longo flashback, é semelhante a Citizen Kane (1941), obra-prima de Welles.

Esse filme, semelhante ao romance dumasiano, apresenta uma percepção ambígua sobre os poderes de Cagliostro, transitando entre sua representação como hipnotista poderoso e, por outro lado, mostrando sua faceta de charlatão. Em uma das cenas iniciais, situada no escritório de Alexandre Dumas, há um diálogo entre o escritor e seu filho, o também literato, Alexandre Dumas Filho. Nesse diálogo, Dumas Pai afirma estar escrevendo um romance que contava a história de Cagliostro ou Joseph Balsamo. O filho ao indagar se esse não seria o famoso charlatão do século XVIII, recebe de seu pai outro questionamento: seria mesmo um charlatão? Dumas, em Le Collier de la reine, também projeta esse olhar que compreende o personagem a partir diversos prismas, concluindo que sua faceta de charlatão era apenas uma delas, como afirma:

O filósofo, o sábio, o profeta, o que fazia pouco da humanidade, o que considerava que até o céu precisava dele, o mesmo homem que tinha sofrido tantas dores em sua vida e tirado tanto sangue do coração dos outros, Cagliostro, o ateu, o charlatão, o cético debochado [...]. Esse homem era um demônio! (DUMAS, 1853a, p. 108; tradução nossa). ${ }^{12}$

Assim, Cagliostro tal como um Doppelgänger, um sósia, possui nas duas obras, romance e filme, uma personalidade dividida e bem semelhante. Durante toda a trama folhetinesca Mémoires d'un médecin são apresentados traços negativos desse personagem, pois ele é manipulador e possui uma relação perniciosa com sua esposa, Lorenza Feliciani, que se casara com ele contra sua vontade, apenas influenciada por seu magnetismo. Porém, ao mesmo tempo, Cagliostro guarda características de um herói ao ser apresentado como aquele que luta pelo fim da opressão na França e em todos os países do mundo, quando impulsiona a Revolução Francesa no seio de uma 
sociedade secreta. Não se trata, portanto, de um herói idealizado e nem mesmo um vilão. Ao contrário, trata-se de um personagem que é perpassado por contradições, apresentando vícios e virtudes, o que denota sua modernidade.

Como salientado por Eco (1991), em O super-homem de massa: retórica e ideologia no romance popular, Cagliostro é o exemplo de um Super-homem de "massa", estabelecido nos romances democráticos da primeira fase dos romancesfolhetins franceses. Esse ideal de herói foi construído como modelo para uma massa de leitores em função da nova fórmula folhetinesca.

Cagliostro, como um Super-homem, é capaz de solucionar os problemas de uma sociedade em crise, fazendo-a voltar a seu equilíbrio. Para Eco (1991), a grande época do folhetim é a mesma das revoluções burguesas da metade do oitocentos. Por isso, estão presentes nessas narrativas certo "reformismo populista e pré-marxista, de que os elementos tópicos do Super-homem e da Sociedade secreta [...] são a manifestação e o instrumento" (ECO, 1991, p. 26).

Assim, Cagliostro, tal como na narrativa dumasiana, no filme é o agente de um complô político revolucionário. Desejava utilizar o escândalo a seu favor, pois tinha a intenção de derrubar a monarquia. Com isso, cria-se uma referência transficcional na construção do personagem dumasiano no ciclo romanesco. Vejamos como no prólogo de Le Mont-Tonnerre, do romance Joseph Balsamo, Cagliostro revela seu pensamento:

[...] um rei velho, enfraquecido, corrompido, mas menos idoso e menos desesperado do que a própria monarquia que ele encarna, está sentado no trono da França. Poucos anos lhe restam para viver. É preciso que a sequência dos fatos futuros seja convenientemente acertada por nós no que se refere ao dia de sua morte. A França é a pedra angular do edifício que os seis milhões de mãos que se levantam sob o comando de um sinal do círculo supremo desloquem esta pedra para o edifício monárquico começar a ruir. E quando esse dia chegar e todos souberem que não existe mais rei em França, os reis da Europa, dentre eles aqueles que estiverem desrespeitosamente sentados em seus tronos, sentirão a vertigem da queda subir-lhes à cabeça e, por iniciativa própria, de mãos dadas, irão se lançar no abismo que este grande desmoronamento do trono de São Luís terá aberto (DUMAS, 1872, p. 25 ; tradução nossa). ${ }^{13}$

No filme, deve-se notar, porém, que apesar de Cagliostro confessar sua intenção de destruição da monarquia, sua motivação está relacionada a um plano pessoal de vingança, pois o Visconde de Montagne havia condenado a mãe de Cagliostro à morte. Assim, o personagem desejava realizar sua vingança contra Montagne e, indiretamente, 
contra toda a classe nobre. Por outro lado, no romance dumasiano a ideia de tomada de poder está relacionada a uma percepção mais ideológica ou política, uma vez que Cagliostro deseja terminar com a corrupção e injustiça da instituição monárquica na França. Nesse sentido, Dumas segue as premissas observadas por Gramsci, em Literatura e Vida Nacional, 111, "Literatura Popular", sobre a função democratizante do romance-folhetim:

\footnotetext{
O romance de folhetim substitui (e ao mesmo tempo favorece) o fantasiar do homem do povo, é um verdadeiro sonhar de olhos abertos... Nesse caso, podemos dizer que no povo o fantasiar é dependente do complexo de inferioridade (social) que determina prolongadas fantasias sobre a ideia de vingança, de punição dos culpados pelos males suportados etc. (GRAMSCI, 1954, p. 108 apud ECO, 1991, p. 63).
}

Deslocando-nos de uma perspectiva comparativista de adaptação, podemos perceber que o filme analisado estabelece um diálogo transficcional com a narrativa dumasiana Le Collier de la reine, no que se refere à participação de Cagliostro como um agente de um complô político-ideológico, capaz de abalar os poderes da Monarquia francesa. Cagliostro é recuperado transficcionalmente em relação ao seu envolvimento no l'affaire, mas, a partir de uma representação dumasiana fundante.

Se nos lembrarmos que Alexandre Dumas pretendeu contar a história da França ao povo para lhes dar cartas de nobreza, seu procedimento literário com referência a Cagliostro mostra que é possível tornar simpáticos mesmo os temas mais complexos, como é o caso da Revolução Francesa, ou os personagens mais controversos, como é o caso de Cagliostro. O escritor faz isso ao colocar no centro do conflito o enigmático personagem Cagliostro, apresentando-o como uma figura polimórfica e de duplo caráter, mas, ao mesmo tempo um Super-homem "de massa", capaz de fazer o povo sonhar com suas ações políticas progressistas.

\section{CONSIDERAÇÕES FINAIS}

Quando abordamos narrativas que ganham o apreço do público, provenientes da cultura dos folhetins, não podemos deixar de observar que muito mais importante do que apresentar um enredo impecável ou não ter furos nas narrativas, são os temas ou personagens a serem recuperados, pois estes perpassaram o imaginário cultural. 
Podemos lembrar quantos não são os personagens que estão guardados em nosso imaginário, como Dom Quixote, Don Juan, Ulisses etc. Tais personagens passam a ser facilmente reconhecíveis por certos traços que os marcam e que reconhecemos imediatamente uma vez que formam um conjunto e carregam um sentido resultante da somatória de vários procedimentos de acréscimo, muitas vezes alguns deles oriundos das diversas adaptações efetuadas a partir de reescrituras artísticas ou de aspectos que se integraram naquela imagem inicial (histórica ou ficcional). Assim é que Dom Quixote tem o caráter do cavaleiro idealista, Don Juan, o do conquistador permanente, e Ulisses, o de um viajante desbravador dos mares.

Acreditamos que, semelhante a esses personagens, o Cagliostro dumasiano também caminhou em uma direção de efetivação de certos traços no imaginário cultural. Isso ocorreu porque Alexandre Dumas, em seu popular ciclo folhetinesco, ao recuperar essa enigmática figura histórica, envolvida em um escândalo que marcou a história francesa, popularizou sua personalidade em tema ficcional, apresentando-o como agente de um complô político, a qual acabou por "colar" em sua imagem através dos tempos e das distintas mídias.

Sabemos que o personagem já havia sido figurado em outras obras literárias, como por exemplo na peça de teatro O Grande-Cophta, de Johann Wolfgang von Goethe publicada em 1791, em que é apresentado como o charlatão Conde di Rostro. Porém, o que Dumas faz é complexificar a compreensão desse personagem, mostrandoo em um representação de Super-homem de "massa", aquele capaz de libertar o povo francês da monarquia. O autor popularizou essa figuração no imaginário coletivo, característica que será recuperada não somente no cinema, mas em outras mídias.

Cagliostro, doravante revisto, "enriquecido" e modificado por Dumas, com a sua nova existência e outros comportamentos, além de seus novos posicionamentos, demonstra que um tema, um aspecto ou um personagem pode não apenas ser objeto da transficionalidade, mas também transitar alterado e renovado por outras mídias, no caso de Cagliostro, o cinema, indo do texto ao filme parcial ou totalmente modificado, seguir sua trajetória intermidiática suscetível, inclusive, de sofrer outras modificações enriquecendo mais ainda o repertório adquirido objeto das mutações.

Essas características assim adquiridas passam a constar como signos incorporados definitivamente no imaginário coletivo, os quais seguem doravante como 
partes integrantes do personagem ou da história, podendo alterar-se renovadamente noutras modalidades intermidiáticas. O caso de Cagliostro, sob a pena de Alexandre Dumas, constitui-se num exemplo desse procedimento, uma vez que o aspecto político revolucionário passou a fazer parte do seu caráter, mesmo se para tanto, essa aquisição entre em contradição com a sua configuração anterior, confirmando assim a teoria da transficionalidade interartística. O cinema não hesitou em adquirir o "pacote" completo vindo do romance e de levá-lo adiante como se sempre assim fora.

\section{Referências}

BAKHTIN, Mikhail. Estética da criação verbal. Tradução Maria Ermantina Galvão G. Pereira. São Paulo: Martins Fontes, 1997.

BARTOLAZZI, Francesco. Comte de Cagliostro. 1868. Disponível em: https://research.britishmuseum.org/research/collection_online/collection_object_details. aspx? objectId=3719652\&page $=1$ \&partId=1 \&peo $A=133205-2$ -

40\&people $=133205 \&$ sortBy=producerSort. Acesso em: 21 nov. 2019. [Catálogo online de British Museum]

BASSAN, Fernande. Joseph Balsamo: une pièce phostume. In: ARROUS, Michel [dir.]. Alexandre Dumas: une lecture de l'histoire. Clamecy: Éditions Maisonneuve et Larose, 2003. p. 265-282.

BAZIN, André. Orson Welles; precedido de "Welles e Bazin", de François Truffaut, e seguido por "Conversas com Orson Welles". Tradução André Telles. Rio de Janeiro Jorge Zahar, 2005.

BLACK MAGIC. Direção: Gregory Ratoff. United Artists. 1949. In: DELCROIX. Black Magic. 2017.

CAGlostro, Alessandro. Traduction d'une lettre écrite par M. Le Comte de Cagliostro a $M^{* * *}$ : Trouvée dans les décombres de la Bastille. Paris: Impr. de Lormel, 1786.

CARREGA, Jorge Manuel Neves. Orson Welles y el cine de Hollywood en la década de 1940. Ámbitos: Revista de estudios de ciencias sociales y humanidades. n. 33, p. 8392, 2015.2 Disponível em: https://helvia.uco.es/bitstream/handle/10396/13141/Ambitos_33_10.pdf?sequence=1\&is Allowed=y. Acesso em: 20 mai. 2021.

DUMAS, Alexandre. Lettre à Jules Michelet. In: LEDDA, Sylvain; SCHOPP, Claude. Cahier de l'Herne, n. 131: Alexandre Dumas. Paris: L'Herne, 2020. [e-Book Kindle]. 
DUMAS, Alexandre. Le Collier de la reine. Paris: Michel Lévy Frères, 1853a. (Bibliothéque contemporaine: Alexandre Dumas: oeuvres complètes, t.2). Disponível em:

https://gallica.bnf.fr/ark:/12148/bpt6k6116143p.r=le\%20collier\%20de\%20la\%20reine\% 20tome\%201?rk=42918;4. Acesso em: 24 mai. 2021.

DUMAS, Alexandre. Le Collier de la reine. Paris: Michel Lévy Frères, 1853b. (Bibliothéque contemporaine: Alexandre Dumas: oeuvres complètes, t.3). Disponível em:

https://gallica.bnf.fr/ark:/12148/bpt6k6121155m.r=le\%20collier\%20de\%20la\%20reine \%20tome\%201?rk=21459;2. Acesso em: 24 mai. 2021.

DUMAS, Alexandre. Mémoires d'un médecin: Joseph Balsamo. Paris: Michel Lévy Frères, 1872. (Alexandre Dumas, oeuvres complètes, t.1). Disponível em: https://gallica.bnf.fr/ark:/12148/bpt6k5474181x?rk=64378;0. Acesso em: 24 mai. 2021.

ECO, Umberto. $O$ super-homem de massa: retórica e ideologia no romance popular. Tradução de Pérola de Carvalho. São Paulo: Perspectiva, 1991. (Coleção Debates).

ECO, Umberto. Migrações de Cagliostro. In: ECO, Umberto. Entre a mentira e a ironia. Tradução de Eliana Aguiar. Rio de Janeiro: Record, 2006. p. 9-28.

GENETTE, Gerard. Palimpsestos: a literatura de segunda mão. Tradução Cibele Braga et al. Belo Horizonte: Viva Voz, 2010.

HAVEN, Marc. $O$ grande mestre oculto: estudo histórico e crítico sobre a alta magia. Tradução Julia Vidili. São Paulo: Madras, 2005.

IMDB. Black Magic. 1949. Disponível em: https://www.imdb.com/title/tt0041182/. Acesso em: 15 mar. 2021.

KRISTEVA, Julia. Sèméiotikè: recherches pour une sémanalyse. Tradução de José Paulo Paes. Paris: Seuil, 1969.

LEDDA, Sylvain; SCHOPP, Claude. Cahier de l'Herne, $n^{\circ}$ 131: Alexandre Dumas. Paris: L'Herne, 2020. [e-Book Kindle].

MENDES, Maria Lúcia Dias. No limiar da História e da memória: um estudo de Mes mémoires, de Alexandre Dumas. Tese (Doutorado em Letras). Programa de Pósgraduação em Língua e Literatura Francesa. USP. São Paulo, 2007. Disponível em: https://www.teses.usp.br/teses/disponiveis/8/8146/tde-01112007 143905/publico/TESE_MARIA_LUCIA_DIAS_MENDES.pdf. Acesso em: 16 mai. 2021.

MEYER, Marlyse. Folhetim: uma história. São Paulo: Companhia das Letras, 1996.

SAINT-GELAIS, Richard. Fictions transfuges: la transfictionnalité et ses enjeux. Paris: Seuil, 2011. 
SAMINADAYAR-PERRIN, Corinne. L'insaisissable corps du peuple dans le cycle révolutionnaire d'Alexandre Dumas. In: ROULIN, Jean-Marie. Corps, littérature et société (1789-1900). Saint-Étienne, PUSE, 2005, p. 141-160. Disponível em: https://publications.univ-st-etienne.fr. Acesso em: 5 abr. 2021.

STAM, Robert. A Literatura através do cinema: realismo, magia e a arte da adaptação. Belo Horizonte: Ed. UFMG, 2008.

Recebido em: 31/05/2021

Aceito em: 04/09/2021

\footnotetext{
${ }^{1}$ Umberto Eco não explicita a significação desse termo. A partir de nossa pesquisa, temos concluído que Cagliostro tem gerado constante interesse através do tempo, seja de seus admiradores, de seus detratores ou até mesmo como uma fonte de curiosidade e de pesquisa, tendo transformado-se em uma personagem lendária.
}

2 "a cristallisé dans l'opinion publique un imaginaire de la corruption tant sociale et politique qu'intellectuelle" (TATIN-GOURIER, 1994, p. 13).

3 "Vous avez plus appris l'histoire au peuple plus que tous les historiens réunis" (DUMAS, 1860 apud LEDDA; SCHOPP, 2020, sem paginação). ${ }^{4}$ A noite de 4 de agosto de 1789 é considerada o ponto alto da Revolução Francesa, pois os deputados dos
Estados Gerais, agora tornados Assembleia Nacional Constituinte, proclamaram o fim dos direitos
feudais e também promulgaram os direitos fundamentais do cidadão.

5 “Apprendre l'histoire au peuple, c'est lui donner ses lettres de noblesse, lettres de noblesse inattaquables et contre lesquelles il n'y aura pas de nuit du 4 août” (Ibid., sem paginação).

6 "se présente explicitement comme une somme narrative synthétisant les analyses de l'historiographie romantique" (SAMINADAYAR-PERRIN, 2005, p. 141).

7 "Madame de La Motte s'était fourvoyée dans chacun de ses calculs. Cagliostro ne se trompa dans aucun. A peine à la Bastille, il s'aperçut que le prétexte lui était donné enfin de travailler ouvertement à la ruine de cette monarchie que, depuis tant d'années, il sapait sourdement avec l'illusionisme et les travaux occultes" (DUMAS, 1853b, p. 249).

8 "Monsieur de Crosne savait de Cagliostro tout ce qu'un habile lieutenant de police peut savoir d'un homme habitant en France, et ce n'est pas peu dire. Il savait tous ses noms passés, tous ses secrets d'alchimiste, de magnétisme et de divination; il savait ses prétentions à l'ubiquité, à la régénération perpétuelle : il le regardait comme un charlatan grand seigneur" (DUMAS, 1853b, p. 230).

${ }^{9}$ Alguns arquivos famosos que divulgaram uma imagem negativa de Cagliostro são as Notícias da infame estadia do Cagliostro em Mitau em 1779 e suas operações mágicas, de Elisabeth von der Recke, e o Compendio da vida e feitos de José Balsamo chamado o Conde de Cagliostro, de Giovani Barbieri.

10 “phénomène par lequel au moins deux textes, du même auteur ou non, se rapportent conjointement à une même fiction que ce soit par reprise de personnages, prolongement d'une intrigue préalable ou partage d'univers fictionnel" (SAINT-GELAIS, 2011, p. 7). 
11 “croiser les champs trop souvent disjoints par la compartimentation académique et certains préjugés encore tenaces” (SAINT-GELAIS, 2011, p. 9).

12 "Le philosophe, le savant, le prophète, le contempteur de l'humanité, celui qui voulait que le ciel luimême comptât avec lui, cet homme qui avait refoulé tant de douleurs chez lui et tiré tant de gouttes do sang du coeur des autres, Cagliostro l'athée, le charlatan, le sceptique rieur [...] Il y avait du démon dans cet homme (DUMAS, 1853a, p. 108).

13 “[...] un roi vieux, timoré, corrompu, moins vieux, moins désespéré encore que la monarchie qu'il représente, siége sur lo trône de France. Quelques années à peine lui restent à vivre. Il faut que l'avenir soit convenablement disposé par nous pour le jour de sa mort. La France est la clef de voûte de l'édifice; que les six millions de mains qui se lèvent à un signe du cercle suprême déracinent cette pierre, et l'édifice monarchique s'écroulera, et le jour où l'on saura qu'il n'y a plus de roi en France, les souverains de l'Europe, les plus insolemment assis sur leurs trônes, sentiront le vertige leur monter au front, et d'euxmêmes ils s'élanceront dans l'abîme qu'aura creusé ce grand écroulement du trône de saint Louis" (DUMAS, 1872, p. 25). 